\title{
Fertility of Dairy Cows after Resynchronization of Ovulation at Three Intervals Following First Timed Insemination
}

\author{
P. M. Fricke, ${ }^{\star}$ D. Z. Caraviello, ${ }^{*}$ K. A. Weigel, ${ }^{\star}$ and M. L. Welle† \\ ${ }^{*}$ Department of Dairy Science, University of Wisconsin, Madison 53706 \\ †Miltrim Farms, Inc., Athens, Wisconsin 54411
}

\begin{abstract}
Lactating Holstein cows $(\mathrm{n}=711)$ on a commercial dairy farm in Wisconsin received a hormonal synchronization protocol to initiate first timed artificial insemination (TAI) on the following postpartum schedule: two injections of $25 \mathrm{mg} \mathrm{PGF}_{2 \alpha}$ at $32 \pm 3 \mathrm{~d}$ and $46 \pm 3 \mathrm{~d}$ (Presynch); $100 \mu \mathrm{g}$ GnRH at $60 \pm 3 \mathrm{~d} ; 25 \mathrm{mg} \mathrm{PGF}_{2 \alpha}$ at $67 \pm 3 \mathrm{~d}$; and $100 \mu \mathrm{g} \mathrm{GnRH}+\mathrm{TAI}$ at $69 \pm 3 \mathrm{~d}$ (Ovsynch). At first TAI, cows were randomly assigned to initiate the first GnRH injection of a hormonal protocol for resynchronization of ovulation (Resynch; $100 \mu \mathrm{g} \mathrm{GnRH}$, d 0, $25 \mathrm{mg} \mathrm{PGF}_{2 \alpha}, \mathrm{d} 7,100 \mu \mathrm{g} \mathrm{GnRH}+$ TAI, d 9) at 19 (D19), 26 (D26), or $33 \mathrm{~d}$ (D33) after first TAI to set up a second TAI service for cows failing to conceive to Ovsynch. Overall pregnancy rate per artificial insemination (PR/AI) to Ovsynch assessed $68 \mathrm{~d}$ after TAI was $31 \%$ and did not differ among treatment groups. For Resynch, PR/AI was assessed 26 d after TAI for D19 and D26 cows and $33 \mathrm{~d}$ after TAI for D33 cows. Overall PR/AI to Resynch was $32 \%$. However, the PR/AI for D26 (34\%) and D33 (38\%) cows to Resynch was greater than for D19 cows (23\%). Cows with a CL at the $\mathrm{PGF}_{2 \alpha}$ injection (D19 cows) or at the first GnRH injection (D26 + D33 cows) of Resynch exhibited greater PR/AI to Resynch compared with cows without a CL. Survival analysis (failure time) of cows in the D26 and D33 treatment groups across the first three TAI services did not differ statistically. Although administration of GnRH to pregnant cows $19 \mathrm{~d}$ after first TAI service did not appear to induce iatrogenic embryonic loss, initiation of Resynch $19 \mathrm{~d}$ after first TAI service resulted in a lower PR/AI compared with initiation of Resynch 26 or $33 \mathrm{~d}$ after first TAI service.
\end{abstract}

(Key words: synchronization, resynchronization, dairy cow, timed artificial insemination)

Abbreviation key: Cosynch = timed insemination coincides with last injection of GnRH in Ovsynch, Ovsynch $=$ synchronization regimen using sequential in-

Received May 30, 2003.

Accepted August 18, 2003.

Corresponding author: P. M. Fricke; e-mail: pmfricke@wisc.edu. jections of $\mathrm{GnRH}$ and $\mathrm{PGF}_{2 \alpha}$ to control ovulation for timed insemination, Presynch $=$ postpartum regimen using 2 injections of $\mathrm{PGF}_{2 \alpha}$ to prepare cows for Ovsynch, PR/AI = pregnancy rate per artificial insemination, Resynch = synchronization regimen using $\mathrm{GnRH}$ and $\mathrm{PGF}_{2 \alpha}$ to resynchronize ovulation in cows after first insemination, $\mathbf{T A I}=$ timed AI.

\section{INTRODUCTION}

The development of hormonal synchronization protocols that allow for timed AI (TAI) have provided a management tool for initiating first-postpartum AI and thereby precisely controlling the voluntary waiting period in lactating dairy cows. A common hormonal protocol for synchronizing ovulation in lactating dairy cows uses injections of GnRH and $\mathrm{PGF}_{2 \alpha}$ (Ovsynch; Pursley et al., 1995; Burke et al., 1996; Pursley et al., 1997a, 1997b) and is an effective method for hormonally programming cows to receive TAI. A presynchronization strategy in which cows receive two injections of $\mathrm{PGF}_{2 \alpha}$ administered $14 \mathrm{~d}$ apart beginning 26 to $28 \mathrm{~d}$ before initiation of Ovsynch (Presynch) has been reported to increase conception rate to TAI in lactating dairy cows compared with Ovsynch alone (Moreira et al., 2001; ElZarkouny et al., 2002; Navanukraw et al., 2002). Many dairy farms in Wisconsin have incorporated synchronization protocols as the primary strategy for submitting cows for first TAI service.

Although reliance on synchronization of ovulation and TAI for improving service rate to first AI reduces the impact of poor estrus detection efficiency, the high AI submission rate to first TAI often is followed by a time lag that can exceed $60 \mathrm{~d}$ before cows failing to conceive are reinseminated. Because AI conception rates of high producing lactating dairy cows are reported to be $40 \%$ or less (Pursley et al., 1997a, 1997b; Fricke et al., 1998; Jobst et al., 2000), 60\% or more of the cows that receive TAI will fail to conceive and, therefore, require a resynchronization strategy for aggressively initiating subsequent AI services. Coupling a nonpregnancy diagnosis with a management decision to rapidly reinitiate AI service improves reproductive efficiency and pregnancy rate by decreasing the interval 
between $\mathrm{AI}$ services, thereby increasing $\mathrm{AI}$ service rate (Fricke, 2002).

Fricke (2002) proposed an aggressive resynchronization protocol in which groups of cows past the voluntary waiting period receive their first postpartum TAI after synchronization of ovulation. On d 18 after TAI, all cows would receive an injection of $\mathrm{GnRH}$ regardless of their pregnancy status. Nonpregnant cows would receive a $\mathrm{PGF}_{2 \alpha}$ injection on $\mathrm{d} 25$ after TAI based on a nonpregnancy diagnosis using ultrasound and would continue resynchronization with Ovsynch, whereas pregnant cows would discontinue the resynchronization protocol. A field trial conducted in Florida in which cows received GnRH on d 20 after TAI followed by transrectal ultrasound and $\mathrm{PGF}_{2 \alpha}$ administration to nonpregnant cows on d 27 was reported by Moreira et al. (2000b). These authors reported an interaction for cows resynchronized with GnRH on d 20 after TAI in which embryonic loss from d 20 to 27 after TAI was increased for bST-treated pregnant cows receiving GnRH but not for non-bST-treated pregnant cows. Because of this observation, this resynchronization strategy was discontinued (Moreira et al., 2000b). Hormonal resynchronization systems that program nonpregnant cows to receive subsequent AI services need to be developed and further assessed so that systematic reproductive management programs can be implemented to aggressively manage reproduction in lactating dairy cows on commercial dairies (Fricke, 2002).

The objective of this study was to evaluate pregnancy rate per AI (PR/AI), and early embryonic loss after initiation of a resynchronization of ovulation protocol initiated at three intervals after first postpartum TAI on a commercial dairy farm in Wisconsin.

\section{MATERIALS AND METHODS}

\section{Farm Description and Data Collection}

Lactating Holstein dairy cows on a commercial dairy farm comprising approximately 1100 lactating cows located in north-central Wisconsin (Athens) were enrolled in this study beginning on May 10, 2001, and ending on May 30, 2002. Cows were housed in free-stall barns and were fed a TMR once daily with ad libitum access to feed and water. Cows were milked 3 times daily at approximately 8 -h intervals, and average milk production per cow was $36.3 \mathrm{~kg} / \mathrm{d}$ during the study period. Synchronization of ovulation for first TAI service and resynchronization of ovulation for second and greater TAI services was performed using i.m. injections of GnRH (100 $\mu$ g of Cystorelin; Merial, Ltd., Duluth, GA) and $\mathrm{PGF}_{2 \alpha}$ (25 $\mathrm{mg}$ of Lutalyse; Pharmacia Animal Health, Kalamazoo, MI).
Cow lists for injection schedules, pregnancy examinations, and reproductive events for individual cows were generated, tracked, and recorded using a commercial on-farm computer software program (Dairy Comp 305, Valley Agricultural Software, Tulare, CA). Cows assigned to the study were coded by treatment, and the "cowfile" was archived and saved every 3 to $5 \mathrm{wk}$ throughout the study to capture individual cow data throughout the study period. Data from cowfile archives were transferred into a computer spreadsheet program (Microsoft Excel 2002, Microsoft Corporation, Redmond, WA) for organization and manipulation of data before statistical analysis using SAS (SAS Inst. Inc., Cary, NC).

\section{Submission of Cows for First Postpartum TAl Service: Presynch + Ovsynch}

Lactating cows ( $\mathrm{n}=711$ ) were allocated weekly to breeding groups, each of which included cows that had calved within a given calendar week $(12.7 \pm 0.7$ cows/ group; range $=3$ to 23 cows/group). In this way, cows were managed in groups to receive hormone injections and first postpartum TAI on 2 preselected days of the week (Tuesdays and Thursdays). All cows received a hormonal synchronization protocol (Presynch + Ovsynch) to receive first postpartum TAI as follows: 25 $\mathrm{mg}$ of $\mathrm{PGF}_{2 \alpha}$ (d $32 \pm 3$ and $46 \pm 3$; Presynch), $100 \mu \mathrm{g}$ GnRH (d $60 \pm 3), 25 \mathrm{mg} \mathrm{PGF}_{2 \alpha}(\mathrm{d} 67 \pm 3)$, and 100 $\mu \mathrm{g}$ GnRH (d $69 \pm 3$ ) postpartum (Ovsynch). All cows received TAI immediately after administration of the second GnRH injection of the Ovsynch protocol (d 0). Thus, the average DIM at first postpartum TAI for all cows enrolled in this experiment was $69 \pm 3 \mathrm{~d}$.

\section{Submission of Cows for Second Postpartum TAI Service: Resynch}

At first TAI service, cows were randomly assigned to each of three treatment groups for resynchronization of ovulation [100 $\mu \mathrm{g}$ of $\mathrm{GnRH}(\mathrm{d}-9) ; 25 \mathrm{mg}$ of $\mathrm{PGF}_{2 \alpha}$ (d -2) and $100 \mu \mathrm{g}$ of GnRH + TAI (d -0)] to induce a second TAI for cows failing to conceive to Ovsynch (i.e., Resynch). Within a breeding group, cows were blocked by parity (primiparous vs. multiparous) as part of the randomization procedure to minimize confounding of this variable among treatment groups. All cows ( $\mathrm{n}=$ 235) in the first group (D19) received a GnRH injection $(100 \mu \mathrm{g}) 19 \mathrm{~d}$ after Ovsynch TAI, a $\mathrm{PGF}_{2 \alpha}$ injection $(25 \mathrm{mg})$ at a nonpregnancy diagnosis using transrectal ultrasound $26 \mathrm{~d}$ after Ovsynch TAI, and a second $\mathrm{GnRH}$ injection $(100 \mu \mathrm{g})$ and Resynch TAI $28 \mathrm{~d}$ after Ovsynch TAI. Cows $(n=240)$ in the second group (D26) received a GnRH injection $(100 \mu \mathrm{g})$ at a nonpregnancy diagnosis 
using transrectal ultrasound $26 \mathrm{~d}$ after Ovsynch TAI, a $\mathrm{PGF}_{2 \alpha}$ injection $(25 \mathrm{mg}) 33 \mathrm{~d}$ after Ovsynch TAI, and a second GnRH injection $(100 \mu \mathrm{g})$ and Resynch TAI 35 $\mathrm{d}$ after Ovsynch TAI. Cows $(\mathrm{n}=236)$ in the third group (D33) received a $\mathrm{GnRH}$ injection $(100 \mu \mathrm{g})$ at a nonpregnancy diagnosis using transrectal ultrasound $33 \mathrm{~d}$ after Ovsynch TAI, a PGF ${ }_{2 \alpha}$ injection $(25 \mathrm{mg}) 40 \mathrm{~d}$ after Ovsynch TAI, and a second GnRH injection $(100 \mu \mathrm{g})$ and Resynch TAI $42 \mathrm{~d}$ after Ovsynch TAI.

\section{Submission of Cows for Third and Greater Postpartum TAI Service}

Throughout the study, cows that failed to conceive to a given TAI service were resynchronized until they became pregnant or were culled from the herd. Because of the potential detrimental effects of $\mathrm{GnRH}$ administered to pregnant cows receiving bST reported by Moreira et al. (2000b), cows in the D19 group that failed to conceive to second TAI service (e.g., Resynch) were resynchronized using the D26 Resynch schedule. Thus, D19 cows did not receive a GnRH injection $19 \mathrm{~d}$ after the first Resynch TAI, but received an injection of GnRH after a nonpregnancy diagnosis $26 \mathrm{~d}$ after the first Resynch TAI. For the third TAI service, cows in the D26 and D33 groups were resynchronized according to the resynchronization schedule for each treatment group. After third TAI service nonpregnant cows in all 3 treatment groups were resynchronized for subsequent TAI services similar to the D26 treatment group. As time progressed, treatment intervals after the first Resynch TAI service were unintentionally extended due to missed injections and failure to locate specific cows on injection days, or intentionally due to injury or illness.

\section{Transrectal Ultrasonography}

All ultrasound examinations and hormone injections were conducted by the herd veterinarian, who is also an ownership partner of the dairy, and who had managed reproduction in dairy cattle using transrectal ultrasonography for the previous $7 \mathrm{yr}$. Pregnancy examinations and hormone injections were conducted immediately after milking by restraining cows in a palpation rail located in the return alley exiting the milking parlor. Visualization of a fluid-filled uterine horn and the presence of a conceptus were used as positive indicators of pregnancy $26 \mathrm{~d}$ after TAI using an ultrasound machine equipped with a transrectal 7.5 MHz linear-array transducer (Aloka 500V; Corometrics Medical Systems, Inc., Wallingford, CT; Fricke et al., 1998). The number of cows diagnosed pregnant to TAI expressed as a percentage of cows within that treatment group receiving TAI was defined as the PR/AI. In addition, both ovaries of each cow were visualized at each pregnancy exam using ultrasound and the presence or absence of a CL was recorded. A cow was recorded as having a CL when the CL diameter was estimated to be $\geq 10 \mathrm{~mm}$. This definition of a CL was adopted because it allowed for rapid and accurate evaluation of CL size using the 10mm hash marks on the ultrasound screen without repeated freezing of the ultrasound image during weekly herd checks.

Pregnancy loss was assessed for cows that conceived to first TAI service during the data collection period. Cows diagnosed pregnant were scheduled for a pregnancy recheck using transrectal ultrasound on d 68 of gestation. A cow that was pregnant at the first pregnancy exam but in which the fetus was dead (assessed by lack of a fetal heartbeat) was considered pregnant and the loss was recorded as occurring on that day. Cows with questionable fetal viability were rechecked 1 wk later. Pregnancy loss for cows diagnosed pregnant to Ovsynch was calculated as the number of pregnant cows that lost a pregnancy by d 68 of gestation expressed as a percentage of cows diagnosed pregnant at 26 (D19 and D26 cows) or 33 d (D33 cows) after Ovsynch TAI.

\section{Temperature Data}

Official temperature data (Midwestern Climate Center, Champaign, IL) reported at a research station located within $20 \mathrm{~km}$ of the farm (Medford, WI; Station ID: 475255 ; latitude: $45^{\circ} 07^{\prime}$, longitude: $90^{\circ} 20^{\prime}$ ) were collected retrospectively. Temperature data were collected for days that TAI was performed for each breeding group throughout the experiment. The high and low temperatures on the day of TAI were recorded, and the high temperature was used to evaluate the effect of temperature at TAI on conception rate for cows within a weekly breeding group.

\section{Statistical Analyses}

Procedure LOGISTIC of SAS (SAS Inst. Inc.) was used to analyze the effect of treatment on PR/AI. The model included treatment, parity, and the two-way interaction, with high temperature at TAI as a regression variable. The effect of AI sire was not included in this model, but sires were distributed evenly among treatments. Within each treatment group, the effect of the presence or absence of a CL on PR/AI was tested by chi-square analysis using the Cochran-Mantel-Haenszel statistic of SAS.

Survival analysis (i.e., failure time analysis), of cows in the D26 and D33 groups was compared across the first three TAI services using a Weibull proportional 
hazards model. Number of days to pregnancy across the first three TAI services was calculated using the hazard function. This function reflects the instantaneous probability (risk) of an individual cow becoming pregnant at time $t$ and was modeled as:

$$
h_{i j k}(\mathrm{t})=h_{0}(t, \gamma, \rho) \exp \left[T_{i} \cdot L_{j} \cdot S_{k}(\mathrm{t})\right]
$$

where

$h_{i j k}(\mathrm{t})=$ hazard function of a given cow at time $t$; $h_{0}(t, \gamma, \rho)=$ Weibull baseline hazard function with scale parameter $\gamma$ and shape parameter $\rho$ (these parameters were estimated from the data);

$T_{i}=$ time-independent effect of treatment;

$L_{j}=$ time-independent effect of parity;

$S_{k}(\mathrm{t})=$ time-dependent effect of season at TAI, assumed to be piecewise constant with change points at each TAI for a given cow.

Four seasons per year were defined, and their change points occurred on March 21, June 21, September 21, and December 21 of each calendar year during the experiment. Observations from cows that became pregnant during the study period were considered as uncensored. Observations from cows that were sold before becoming pregnant, cows that failed to become pregnant by the end of the study period, and cows that experienced embryonic loss after a positive pregnancy diagnosis were considered as censored. For cows that experienced embryonic loss, the date of the last TAI service was used as the time of censoring. The Survival Kit Version 3.12, a set of Fortran programs written by Ducrocq and Sölkner (1998), was used for the survival analysis. Details regarding the algorithms for estimation are given by Ducrocq (1994), and theoretical aspects are discussed by Ducrocq and Casella (1996).

\section{RESULTS AND DISCUSSION}

\section{Resynchronization Strategy}

Reproductive management protocols that allow for TAI and minimize or eliminate visual estrus detection must be practical to implement within the day-to-day operation of a dairy farm or the protocol will fail due to lack of compliance. In the present study, submission of cows for first postpartum TAI service was scheduled so that the first 4 injections of the Presynch plus Ovsynch protocol occurred on Tuesdays followed by the second GnRH injection and TAI occurring on Thursdays. This TAI schedule for both the Ovsynch and Resynch protocols used in this study represent a variation in which the TAI is performed during the same cowhandling period as the second GnRH (Cosynch), thereby eliminating one handling period compared with the first reported Ovsynch protocol (Pursley et al., 1995). Although the timing of insemination in a Cosynch strategy may not maximize conception rate to TAI (Pursley et al, 1998; Dalton et al., 2001), use of Cosynch allows for cows to be handled at the same time of the day on different days, thereby allowing for cows to be restrained in self-locking head gates or a palpation rail after a specified milking in $3 \times$ milking systems in which cow-handling periods are dictated by the milking routine rather than by preselected protocol intervals.

Initiation times for Resynch for each of the 3 treatment groups in this study were chosen to occur on Tuesdays so that injection schedules would remain consistent for all cows assigned to weekly breeding groups at any given time. To adhere to the Tuesday/Thursday schedule, all pregnancy examinations were conducted on Tuesdays. To fit the reproductive management system, the first pregnancy examination using transrectal ultrasound was conducted $26 \mathrm{~d}$ after TAI for the D19 and D26 cows, and $33 \mathrm{~d}$ after TAI for the D33 cows. Under most on-farm conditions, pregnancy diagnosis can be rapidly and accurately diagnosed using transrectal ultrasound as early as $26 \mathrm{~d}$ post AI (Kastelic et al., 1991; Filteau and DesCôteaux, 1998). Sensitivity and specificity of pregnancy diagnosis using ultrasound was 45 and $82 \%$, respectively, when conducted between 21 and $25 \mathrm{~d}$ post AI but increased to 98 and $88 \%$, respectively, when conducted between 26 and $33 \mathrm{~d}$ post AI (Pieterse et al., 1990a). Thus, the reproductive management systems assessed in this trial allow for administration of all hormone injections, Ovsynch and Resynch TAI services, and pregnancy examinations to be restricted regularly to either Tuesdays or Thursdays.

\section{Pregnancy Rate per Artificial Insemination After First TAI Service: Ovsynch}

Inherent to the experimental design, first assessment of pregnancy status was not conducted at the same interval after the Ovsynch TAI among the three treatment groups. Pregnancy status after the Ovsynch TAI was first assessed $26 \mathrm{~d}$ after TAI for cows in the D19 and D26 groups, whereas pregnancy status was assessed 33 d post Ovsynch TAI for cows in the D33 group (Table 1). Overall PR/AI to Ovsynch was $40 \%$ (286/711) and was greater for D19 and D26 cows than for D33 cows (Table 1). This difference is likely due to a greater period in which embryonic loss can occur in the D33 cows due to the increased interval from TAI to pregnancy diagnosis (26 vs. $33 \mathrm{~d}$ ). When pregnancy status was reassessed for all treatment groups at $68 \mathrm{~d}$ after $\mathrm{Ov}$ - 
Table 1. Pregnancy rate per artificial insemination (PR/AI) and pregnancy loss after timed artificial insemination (TAI) to Ovsynch.

\begin{tabular}{lllll}
\hline & \multicolumn{3}{c}{ Treatment group } & \\
\cline { 2 - 4 } Item & $\mathrm{D} 19$ & $\mathrm{D} 26$ & $\mathrm{D} 33$ & Overall \\
\hline Interval from Ovsynch TAI to 1st pregnancy exam (d) & 26 & 26 & 33 & \\
PR/AI at 1st pregnancy exam, \% & $46^{\mathrm{a}}$ & $42^{\mathrm{a}}$ & $33^{\mathrm{b}}$ & 40 \\
(no./no.) & $(108 / 235)$ & $(101 / 240)$ & $(77 / 236)$ & $(286 / 711)$ \\
Interval from Ovsynch TAI to 2nd pregnancy exam (d) & 68 & 68 & 68 & - \\
PR/AI at 2nd pregnancy exam, \% & 33 & 30 & 29 & 31 \\
(no./no.) & $(78 / 235)$ & $(73 / 240)$ & $(68 / 236)$ & $(219 / 711)$ \\
Interval between pregnancy exams (d) & 42 & 42 & 35 & - \\
Pregnancy loss, \% & $28^{\mathrm{a}}$ & $28^{\mathrm{a}}$ & $12^{\mathrm{b}}$ & 23 \\
(no./no.) & $(30 / 108)$ & $(28 / 101)$ & $(9 / 77)$ & $(67 / 286)$ \\
\hline
\end{tabular}

${ }^{\mathrm{a}, \mathrm{b}}$ Within a row, percentages with different superscripts differ $(P<0.01)$ among treatment groups.

synch TAI, overall PR/AI to Ovsynch was 31\% (219/ 711) and did not differ among treatments (Table 1). Thus, differences in PR/AI at the first pregnancy exam and pregnancy losses between the first and second pregnancy exams among treatment groups likely represent an artifact of time of assessment of pregnancy status after TAI inherent to the experimental design rather than to treatment differences.

For Ovsynch, PR/AI for the D19 and D26 cows in the present study is similar to that reported previously using either a 12-d (Moreira et al., 2001; El-Zarkouny et al., 2002) or a 14-d (Navanukraw et al., 2002) interval between the second $\mathrm{PGF}_{2 \alpha}$ injection of Presynch and the first $\mathrm{GnRH}$ injection of the Ovsynch protocol. Although this study was not designed to evaluate the effect of presynchronization on PR/AI, the 8-percentage-unit difference in overall PR/AI to the Presynch/ Ovsynch versus first Resynch TAI (Table 1 vs. Table 3) in the present study may reflect the increased PR/AI to TAI due to presynchronization reported previously (Moreira et al., 2001; El-Zarkouny et al., 2002; Navanukraw et al., 2002).

Pregnancy loss contributes to reproductive inefficiency because fertility assessed at any point during pregnancy is a function of both conception rate and pregnancy loss (Fricke, 2002). For cows diagnosed pregnant to Ovsynch, overall pregnancy loss occurring between the first pregnancy exam and $68 \mathrm{~d}$ of gestation was 23\% (67/286) and was greater for D19 and D26 cows than for D33 cows (Table 1). Although not a direct comparison, the numbers of pregnancies lost in each treatment group almost fully accounted for differences in PR/AI to the first pregnancy exam after the Ovsynch TAI among treatment groups (Table 1). Because cows diagnosed pregnant at an early ultrasound exam have a greater risk of early embryonic loss, these cows must undergo subsequent pregnancy examinations to identify and rebreed cows that experience such loss (Fricke, 2002). If left unidentified, cows experiencing embryonic loss after an early pregnancy diagnosis would actually reduce reproductive efficiency by extending intervals from calving to conception.

Of cows diagnosed pregnant at $28 \mathrm{~d}$ post TAI, 10 to $16 \%$ experience embryonic loss by $56 \mathrm{~d}$ after TAI (Mee et al., 1994; Vasconcelos et al., 1997; Fricke et al., 1998). Although the magnitude of embryonic loss in this study is greater that that reported in previous studies, the period over which loss was assessed beginning earlier in gestation ( 26 to $33 \mathrm{~d}$ ). In a previous study (Vasconcelos et al., 1997), pregnancy loss in lactating dairy cows was $11 \%$ from 28 to $42 \mathrm{~d}, 6 \%$ from 42 to $56 \mathrm{~d}$, and $2 \%$ from 56 to $98 \mathrm{~d}$ post AI, suggesting that losses are highest early and subsequently decrease as gestation ensues. In the present study, at least $46 \%$ of cows in the D19 group were pregnant at the time of $\mathrm{GnRH}$ administration (Table 1), whereas GnRH was administered only to cows after a nonpregnancy diagnosis in the D26 group. Both PR/AI and embryonic losses were similar between these treatment groups (Table 1), suggesting that no iatrogenic embryonic loss occurred in pregnant cows receiving GnRH in the D19 group from d 26 to 68 of gestation. Although the present study does not include the appropriate control groups to substantiate or refute the observation of Moreiera et al. (2000b), a study reported during the course of this experiment in which GnRH was administered to cows $21 \mathrm{~d}$ after AI before a pregnancy examination $28 \mathrm{~d}$ after AI showed no negative effect of GnRH on conception rate or embryonic losses compared to untreated cows (Chebel et al., 2002). Collectively, these data support that $\mathrm{GnRH}$ does not induce iatrogenic embryonic loss when administered to pregnant cows.

\section{Pregnancy Rate per Artificial Insemination After Second TAI Service: Resynch}

A total of 41 cows diagnosed nonpregnant to Ovsynch were not enrolled for Resynch for second TAI service 
Table 2. Outcomes for cows diagnosed nonpregnant to Ovsynch that were not enrolled for Resynch for second TAI service.

\begin{tabular}{|c|c|c|c|c|}
\hline \multirow[b]{2}{*}{ Outcome } & \multicolumn{4}{|c|}{ Treatment group } \\
\hline & $\begin{array}{l}\text { Day } 19 \\
(\mathrm{n}=127) \\
\mathrm{n}(\%)\end{array}$ & $\begin{array}{l}\text { Day } 26 \\
(\mathrm{n}=139 \\
\mathrm{n}(\%)\end{array}$ & $\begin{array}{l}\text { Day } 33 \\
(\mathrm{n}=159) \\
\mathrm{n}(\%)\end{array}$ & $\begin{array}{l}\text { Overall } \\
(\mathrm{n}=425) \\
\mathrm{n}(\%)\end{array}$ \\
\hline Died & $0(0.0)$ & $1(0.7)$ & $0(0.0)$ & $1(0.2)$ \\
\hline AI to a detected estrus & $5(3.9)$ & $10(7.2)$ & $9(5.7)$ & $24(5.6)$ \\
\hline Marked as "do not breed" & $1(0.8)$ & $7(5.0)$ & $6(3.8)$ & $14(3.3)$ \\
\hline Sold & $1(0.8)$ & $0(0.0)$ & $1(0.6)$ & $2(0.5)$ \\
\hline Total & $7(5.5)$ & $18(12.9)$ & $16(10.1)$ & $41(9.6)$ \\
\hline
\end{tabular}

for various reasons (Table 2). Only 5.6\% of cows failing to conceive to Ovsynch were visually detected in estrus and inseminated (Table 2), underscoring the reliance of this farm on TAI for inseminating cows. Overall PR/ AI to Resynch was $32 \%$ and was greater for D26 and D33 cows than for D19 cows (Table 3). Although PR/AI to TAI protocols can vary widely among farms, PR/AI after Resynch for the D26 and D33 cows in the present study is similar to conception rate after Ovsynch reported previously (Pursley et al., 1995; Fricke et al., 1998; Jobst et al., 2000).

Specific reasons for the poor Resynch PR/AI for D19 cows in the present study are unknown. Success of the Ovsynch protocol in lactating dairy cows varies depending on cyclicity status and stage of the estrous cycle at initiation of Ovsynch (Moreira et al., 2001). Stage of the estrous cycle at initiation of Ovsynch affects synchronized ovulation rate to the first GnRH injection and subsequent conception rate to TAI (Vasconcelos et al., 1999; Moreira et al., 2000a). In addition, cows initiating the Ovsynch protocol during early to mid diestrus (d 5 to 12 of the estrous cycle) when serum progesterone concentrations were high, ovulated smaller follicles and had greater conception rates than cows initiating Ovsynch during metestrus, late diestrus, or proestrus (Vasconcelos et al, 1999). Assuming an average estrous cycle duration of 23 d (Savio et al., 1990; Pursley et al., 1993; Sartori, 2002) for cows failing to conceive to Ovsynch, initiation of Resynch in the present study would approximately coincide with three stages of the estrous cycle: proestrus (D19), metestrus (D26), and diestrus (D33). Under this scenario and based on previous reports (Vasconcelos et al., 1999; Moreira et al., 2000a), initiation of Resynch $33 \mathrm{~d}$ after TAI should yield the highest PR/AI. In the present study, PR/AI to Resynch was numerically greatest (38\%) for the D33 group but not statistically greater than the D26 group (Table 3). This occurred in spite of the longer interval from Resynch TAI to pregnancy diagnosis in the D33 group (33.7 d) compared to the D26 group (26.6 d) and in addition to the expected increased incidence of embryonic loss among treatment groups similar to that observed for PR/AI to Ovsynch.

Progesterone status or the presence or absence of a CL at Resynch initiation, both of which are related to stage of the estrous cycle also can affect PR/AI. Although progesterone status during the Resynch protocol was not assessed in the present study, presence or absence of a CL at pregnancy examinations was recorded. Although these data are limited in the present study because prostaglandin responsiveness and presence or absence of ovarian follicles was not known, these data are pertinent because this information can be collected via transrectal ultrasonography or rectal palpation by a bovine practitioner in a commercial setting. In the present study, PR/AI was nearly triple $(P<0.05)$ for D19 cows with a CL (28\%) than for cows without a CL $(10 \%)$ at the $\mathrm{PGF}_{2 \alpha}$ injection of Resynch (Table 4). Nearly one-fourth of D19 cows lacked a CL at PGF $2 \alpha$ administration suggesting that induction of ovulation

Table 3. Pregnancy rate per artificial insemination (PR/AI) after timed artificial insemination (TAI) to Resynch beginning 19, 26, or $33 \mathrm{~d}$ after first TAI.

\begin{tabular}{|c|c|c|c|c|}
\hline \multirow[b]{2}{*}{ Item } & \multicolumn{3}{|c|}{ Treatment group } & \multirow[b]{2}{*}{ Overall } \\
\hline & D19 & $\mathrm{D} 26$ & D33 & \\
\hline $\begin{array}{l}\text { Mean ( } \pm \text { SEM) interval (d) from Resynch } \\
\text { TAI to pregnancy exam (range) }\end{array}$ & $\begin{array}{l}27.1 \pm 0.4 \\
(26 \text { to } 54)\end{array}$ & $\begin{array}{l}26.6 \pm 0.2 \\
(26 \text { to } 40)\end{array}$ & $\begin{array}{l}33.7 \pm 0.4 \\
(26 \text { to } 75)\end{array}$ & - \\
\hline $\begin{array}{r}\text { PR/AI, \% } \\
\text { (no./no.) }\end{array}$ & $\begin{array}{c}23^{\mathrm{a}} \\
(28 / 120)\end{array}$ & $\begin{array}{l}34^{\mathrm{b}} \\
(41 / 121)\end{array}$ & $\begin{array}{c}38^{\mathrm{b}} \\
(54 / 143)\end{array}$ & $\begin{array}{c}32 \\
(123 / 384)\end{array}$ \\
\hline
\end{tabular}

${ }^{\mathrm{a}, \mathrm{b}}$ Within a row, percentages with different superscripts differ $(P<0.01)$ among treatment groups. 
Table 4. Effect of the presence or absence of a corpus luteum (CL) at the first GnRH injection (d 19) or $\mathrm{PGF}_{2 \alpha}$ injection (d 26 and 33) on pregnancy rate per artificial insemination (PR/AI) after Resynch.

\begin{tabular}{|c|c|c|c|c|c|c|}
\hline \multirow[b]{3}{*}{ Treatment } & \multirow[b]{3}{*}{ Item } & \multicolumn{4}{|c|}{ Presence of a $\mathrm{CL}^{1}$ at: } & \multirow[b]{3}{*}{$P$-value } \\
\hline & & \multicolumn{2}{|c|}{ First GnRH injection } & \multicolumn{2}{|c|}{$\mathrm{PGF}_{2 \alpha}$ injection } & \\
\hline & & Yes & No & Yes & No & \\
\hline \multirow{3}{*}{ Day 19} & $\mathrm{n}$ & - & - & 91 & 29 & \multirow[b]{3}{*}{0.04} \\
\hline & $\%$ of cows & - & - & 76 & 24 & \\
\hline & PR/AI (\%) & - & - & 28 & 10 & \\
\hline \multirow{3}{*}{ Day 26} & $\mathrm{n}$ & 82 & 39 & - & - & \multirow{4}{*}{0.39} \\
\hline & $\%$ of cows & 68 & 32 & - & - & \\
\hline & PR/AI (\%) & 35 & 31 & - & - & \\
\hline \multirow{3}{*}{ Day 33} & $\mathrm{n}$ & 112 & 31 & - & - & \\
\hline & $\%$ of cows & 78 & 22 & - & - & \multirow{3}{*}{0.09} \\
\hline & PR/AI (\%) & 41 & 26 & - & - & \\
\hline \multirow{3}{*}{ Day $26+33$} & $\mathrm{n}$ & 194 & 70 & - & - & \\
\hline & $\%$ of cows & 74 & 27 & - & - & \multirow[b]{2}{*}{0.09} \\
\hline & PR/AI (\%) & 39 & 29 & - & - & \\
\hline
\end{tabular}

${ }^{1} \mathrm{~A}$ cow was recorded as having a CL present when the CL diameter was estimated to be $=10 \mathrm{~mm}$ at the ultrasound examination.

by the first GnRH injection of Resynch may have been poor, because all of those cows received GnRH $7 \mathrm{~d}$ before the pregnancy diagnosis. Similarly, PR/AI to Resynch tended to be greater $(P=0.09)$ for $\mathrm{D} 26+\mathrm{D} 33$ cows with a CL (39\%) than for cows without a CL (29\%) at the first GnRH injection of Resynch (Table 4). Based on previous reports (Vasconcelos et al., 1999; Moreira et al., 2000a), these cows may have been at an unfavorable stage of the estrous cycle when Resynch was initiated. Interestingly, presence or absence of a CL at Resynch initiation did not affect PR/AI in the D26 group. Perhaps ovulatory response to the first GnRH injection was high in this group because they were in the early stage of the estrous cycle when a dominant follicle with ovulatory capacity is present (Vasconcelos et al., 1999). Further experiments are required to define the physiology that determines PR/AI after initiation of Resynch at various intervals post TAI.

\section{Survival Analysis}

Survival analysis is a powerful methodology for evaluation of reproductive data, because it allows the inclusion of time-dependent covariates, accommodates skewed or unknown distributions of time to pregnancy, and properly handles censored (cows failing to become pregnant) records (Smith and Quaas, 1984; Ducrocq and Solkner, 1998; Vukasinovic, 1999). Time from first TAI to pregnancy in the D26 and D33 groups was compared across the first three TAI services using a Weibull proportional hazards model. Cows in the D19 group were excluded from this analysis because these cows initiated Resynch after the Ovsynch TAI using the D19 treatment schedule but were shifted to the D26 Resynch schedule for third TAI service. For cows that experi- enced embryonic loss, the date of the last TAI service was used as time of censoring. Censoring of cows that experienced embryonic loss in this way adjusted for differences in PR/AI observed between the D26 and D33 treatment groups that were artifacts of the difference in length of the TAI to pregnancy diagnosis interval between treatments. Although cows in the D33 group had a 5\% greater risk of pregnancy across the first three TAI services than cows in the D26 group (Table 5), this difference was not statistically significant. Thus, the 7d advantage of the D26 group over the D33 group was negated by the increased rate of embryonic loss observed in the D26 group due to the earlier pregnancy exam and the longer period in which embryonic loss could occur.

High ambient temperatures at TAI affected PR/AI in the present study. Heat stress affects reproductive performance in dairy cows by affecting both oocyte quality during the periovulatory period and increasing early embryonic loss (Hansen et al., 1992; Sartori et al., $2002)$. Cows had a $41 \%$ greater $(P=0.05)$ risk of pregnancy during fall 2001 and a $71 \%$ greater $(P<0.01)$ risk of pregnancy during winter 2001 to 2002 compared with summer 2001 (Table 5). In addition, retrospective analysis of official temperature data showed a relationship between monthly PR/AI to Ovsynch and Resynch TAI versus mean high daily temperature at TAI for the breeding groups (Table 6 and Figure 1). For Ovsynch, a $1^{\circ} \mathrm{C}$ increase in mean daily high temperature at TAI resulted in a 2-percentage-unit decrease in PR/AI, whereas for the first Resynch, a $1^{\circ} \mathrm{C}$ increase in mean daily high temperature at TAI resulted in a 3-percentage-unit decrease in PR/AI to TAI (Table 6). Although heat stress has been well documented in Southern US states (Hansen et al., 1992), these observations high- 
Table 5. Estimated risk of pregnancy from the Weibull model analysis of time from first timed artificial insemination to pregnancy. Risk ratios were constrained to 1.0 for fourth parity, Summer 2001, and treatment D26 (class with the lowest risk of pregnancy).

\begin{tabular}{llccc}
\hline Covariate & Class & $\begin{array}{c}\text { Uncensored } \\
\text { failures }\end{array}$ & Risk ratio & $P$-value \\
\hline Parity & 1 & 91 & 1.08 & 0.80 \\
& 2 & 154 & 1.05 & 0.88 \\
& 3 & 25 & 1.04 & 0.91 \\
Season of TAI & 4 & 11 & 1.00 & - \\
& Spring 2001 & 26 & 1.16 & 0.51 \\
& Summer 2001 & 63 & 1.00 & 0.05 \\
& Fall 2001 & 71 & 1.41 & $<0.01$ \\
Treatment & Winter 2001-2002 & 79 & 1.71 & 0.30 \\
& Spring 2002 & 44 & 1.23 & - \\
& D26 & 133 & 1.00 & 0.69 \\
\hline
\end{tabular}

${ }^{1}$ Probability of a significant difference from the class that was constrained to 1.0.

light the impact of heat stress on PR/AI in lactating cows in Northern US states during seasons and months when ambient temperatures are high.

\section{CONCLUSIONS}

Results from this study argue against the D19 group as a viable resynchronization strategy based on the poor PR/AI after the Resynch TAI. Because time to pregnancy did not differ significantly between the D26 and D33 groups in this study, several resynchronization strategies might be considered. A veterinarian who can accurately determine pregnancy status via rectal palpation $33 \mathrm{~d}$ post TAI could incorporate the D33 Resynch strategy without reliance on transrectal ultrasound for early pregnancy diagnosis. Assuming that administration of GnRH to pregnant cows $33 \mathrm{~d}$ after TAI does not induce iatrogenic embryonic loss, all cows could be administered $\mathrm{GnRH}$ at $33 \mathrm{~d}$ after TAI. Cows would then receive $\mathrm{PGF}_{2 \alpha}$ at a nonpregnancy diagnosis via rectal palpation conducted $1 \mathrm{wk}$ later. Alternatively, veterinarians who have incorporated transrectal ultrasound for reproductive management could adopt the D26 Resynch strategy as reported herein, or alternatively, could administer GnRH to all cows regardless of their pregnancy status $26 \mathrm{~d}$ post TAI. Cows would then receive $\mathrm{PGF}_{2 \alpha}$ at a nonpregnancy diagnosis via transrectal ultrasound conducted 1 wk later.

Table 6. Mean high and low temperature at timed artificial insemination (TAI) and pregnancy rate per artificial insemination (PR/AI) to TAI by month.

\begin{tabular}{|c|c|c|c|c|c|}
\hline \multirow[b]{3}{*}{ Month } & \multirow{2}{*}{\multicolumn{2}{|c|}{ Temperature $^{1}(\mathrm{C})$}} & \multicolumn{3}{|c|}{ PR/AI } \\
\hline & & & \multirow{2}{*}{$\begin{array}{l}\text { Ovsynch TAI } \\
\% \text { (no./no.) }\end{array}$} & \multirow{2}{*}{$\begin{array}{l}\text { Resynch TAI } \\
\% \text { (no./no.) }\end{array}$} & \multirow{2}{*}{$\begin{array}{l}\text { All TAI } \\
\% \text { (no./no.) }\end{array}$} \\
\hline & Low & High & & & \\
\hline May, 2001 & 7.1 & 19.8 & $42(24 / 57)$ & - & $42(24 / 57)$ \\
\hline Jun, 2001 & 11.8 & 23.1 & $36(21 / 59)$ & $21(5 / 24)$ & $31(26 / 83)$ \\
\hline Jul, 2001 & 13.9 & 26.8 & $23(13 / 56)$ & $30(10 / 33)$ & $26(23 / 89)$ \\
\hline Aug, 2001 & 14.6 & 26.8 & $15(8 / 52)$ & $16(7 / 44)$ & $16(15 / 96)$ \\
\hline Sep, 2001 & 7.7 & 19.4 & $43(21 / 49)$ & $26(9 / 35)$ & $36(30 / 84)$ \\
\hline Oct, 2001 & 0.7 & 12.6 & $50(17 / 34)$ & $39(12 / 31)$ & $45(29 / 65)$ \\
\hline Nov, 2001 & 0.3 & 9.6 & $39(24 / 62)$ & $22(6 / 27)$ & $34(30 / 89)$ \\
\hline Dec, 2001 & -8.1 & -0.2 & $43(26 / 61)$ & $36(8 / 22)$ & $41(34 / 83)$ \\
\hline Jan, 2002 & -10.9 & -1.9 & $40(30 / 75)$ & $45(19 / 42)$ & $42(49 / 117)$ \\
\hline Feb, 2002 & -10.1 & 0.7 & $57(37 / 65)$ & $46(13 / 28)$ & $54(50 / 93)$ \\
\hline Mar, 2002 & -10.7 & -0.1 & $52(22 / 42)$ & $50(15 / 30)$ & $51(37 / 72)$ \\
\hline Apr, 2002 & -0.5 & 10.0 & $42(24 / 57)$ & $26(5 / 19)$ & $38(29 / 76)$ \\
\hline May, 2002 & 3.5 & 15.6 & $45(19 / 42)$ & $22(7 / 32)$ & $35(26 / 74)$ \\
\hline Jun, 2002 & 13.2 & 24.1 & - & $46(6 / 13)$ & $46(6 / 13)$ \\
\hline Jul, 2002 & 16.4 & 28.2 & - & $25(1 / 4)$ & $25(1 / 4)$ \\
\hline Overall & 3.3 & 14.3 & $40(286 / 711)$ & $32(123 / 384)$ & $37(409 / 1095)$ \\
\hline
\end{tabular}

${ }^{1}$ Official temperature data (Midwestern Climate Center, Champaign, IL) reported at a research station located within 12 miles of the farm. For Ovsynch, a $1^{\circ} \mathrm{C}$ increase in mean daily high temperature at TAI resulted in a 2-percentage-unit decrease in PR/AI, whereas for the first Resynch, a $1^{\circ} \mathrm{C}$ increase in mean daily high temperature at TAI resulted in a 3-percentage-unit decrease in PR/AI to TAI. 


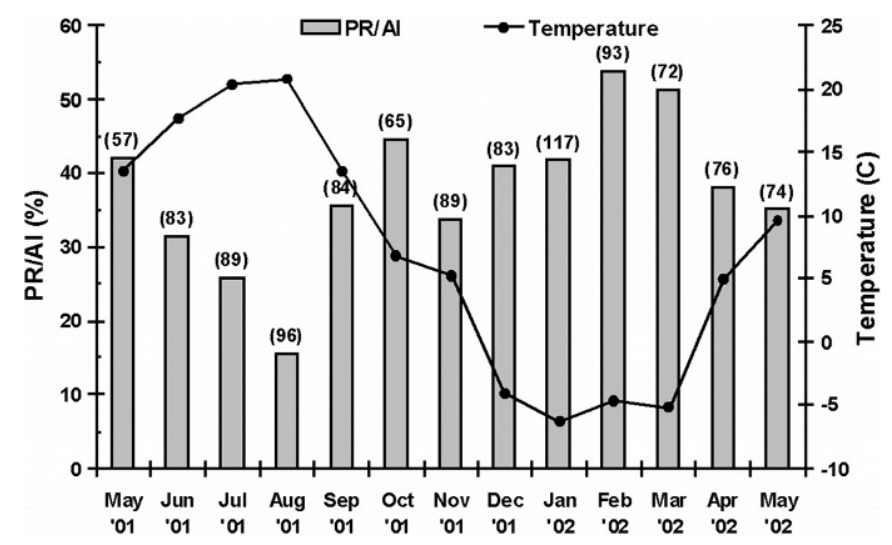

Figure 1. Effect of mean high ambient temperature on pregnancy rates to timed AI (TAI) by month. Pregnancy rate per artificial insemination (PR/AI) represents all Ovsynch and Resynch TAI services during each respective month. Numbers above bars are the total number of TAI services for each month. Temperature data represents the mean high daily temperature at the time of TAI for all TAI services occurring each month. Cows had greater $(P=0.05)$ pregnancy rates during fall and winter months compared to summer months.

Adoption of systematic Ovsynch/Resynch strategies by large dairy operations may provide a research model to investigate important aspects of reproductive biology in lactating dairy cows. For example, systematic resynchrony effectively eliminates the vagaries of low estrous detection rates when trying to identify factors associated with differences between cows that influence success or failure to initiate pregnancy. Using records from large herds adopting systematic resynchrony systems, individual cows that lose or retain pregnancies could be coupled with health, production, and environmental information obtained for the same cows at resynchrony preceding subsequent inseminations. Future studies may be developed to answer these as well as other questions regarding reproductive events in dairy cattle in herds using systematic synchronization and resynchronization systems.

Although use of ultrasound is not required to implement either the D26 or D33 Resynch protocols, use of ultrasound for reproductive management of lactating dairy cows is not without benefit (Fricke, 2002). The observation that cows without a CL at initiation of Resynch had poor conception rates provides a management opportunity to detect such cows and employ an alternative treatment strategy. Because specificity and sensitivity of detection of ovarian structures is greater for ultrasound than for rectal palpation (Pieterse et al., $1990 \mathrm{~b}$ ), use of ultrasound may be beneficial if such a differential management strategy is developed. Finally, it is possible that the optimal resynchronization strategy for this herd may not perform optimally in other herds. A difference in populations with varying propor- tions of cows exhibiting two or three follicular waves per cycle has been suggested to impact conception rate to Ovsynch (Cordoba and Fricke, 2002). Further research is needed to further develop successful resynchronization strategies for managing reproduction in lactating dairy cows.

\section{ACKNOWLEDGMENTS}

The authors thank Gary Neubauer and Pharmacia Animal Health, Kalamazoo, MI, for providing Lutalyse for this project and Miltrim Farms Inc. for use of their cows and facilities.

\section{REFERENCES}

Burke, J. M., R. L. de la Sota, C. A. Risco, C. R. Staples, E. J. P. Schmitt, and W. W. Thatcher. 1996. Evaluation of timed insemination using a gonadotropin-releasing hormone agonist in lactating dairy cows. J. Dairy Sci. 79:1385-1393.

Chebel, R. C., J. E. P. Santos, S. O. Juchem, R. L. A. Cerri, K. N. Galvao, and W. W. Thatcher. 2002. Effect of resynchronization with GnRH on day 21 after artificial insemination on conception rate and pregnancy loss in lactating dairy cows. J. Dairy Sci. 85(Suppl. 1):265. (Abstr.)

Cordoba, M. C., and P. M. Fricke. 2002. Initiation of the breeding season in a grazing-based dairy by synchronization of ovulation. J. Dairy Sci. 85:1752-1763.

Dalton, J. C., S. Nadir, J. H. Bame, M. Noftsinger, R. L. Nebel, and R. G. Saacke. 2001. Effect of time of insemination on number of accessory sperm, fertilization rate, and embryo quality in nonlactating dairy cattle. J. Dairy Sci. 84:2413-2418.

Ducrocq, V. 1994. Statistical analysis of length of productive life for dairy cows of the Normande breed. J. Dairy Sci. 77:855-866.

Ducrocq, V., and G. Casella. 1996. A Bayesian analysis of mixed survival models. Genet. Sel. Evol. 28:505-529.

Ducrocq, V., and J. Sölkner. 1998. The Survival Kit-V3.0: A Package for Large Analyses of Survival Data. Proc. 6th World Congr. Genet. Appl. Livest. Prod., Armidale, Australia 22:51-52.

El-Zarkouny, S. Z., B. A. Hensley, and J. S. Stevenson. 2002. Estrus, ovarian, and hormonal responses after resynchronization with progesterone and estrogen in lactating dairy cows of unknown pregnancy status. J. Dairy Sci. 85(Suppl. 1):98(Abstr).

Filteau, V., and L. DesCôteaux. 1998. Predictive values of early pregnancy diagnosis by ultrasonography in dairy cattle. Proc. AABP Annu. Mtg., Spokane, WA 31:170-171.

Fricke, P. M. 2002. Scanning the future-Ultrasonography as a reproductive management tool for dairy cattle. J. Dairy Sci. 85:1918-1926.

Fricke, P. M., J. N. Guenther, and M. C. Wiltbank. 1998. Efficacy of decreasing the dose of GnRH used in a protocol for synchronization of ovulation and timed AI in lactating dairy cows. Theriogenology 50:1275-1284.

Hansen, P. J., W. W. Thatcher, and A. D. Ealy. 1992. Methods for reducing effects of heat stress on pregnancy. Pages 116-125 in Large Dairy Herd Management (Van Horn, H. H. and C. J. Wilcox, Eds.). Am. Dairy Sci. Assoc., Savoy, IL.

Jobst, S. M., R. L. Nebel, M. L. McGilliard, and K. D. Pelzer. 2000. Evaluation of reproductive performance in lactating dairy cows with prostaglandin $\mathrm{F}_{2 \alpha}$, gonadotropin-releasing hormone, and timed artificial insemination. J. Dairy Sci. 83:2366-2372.

Kastelic, J. P., D. R. Bergfelt, and O. J. Ginther. 1991. Ultrasonic detection of the conceptus and characterization of intrauterine fluid on days 10 to 22 in heifers. Theriogenology 35:569-581.

Mee, J. F., D. P. Ryan, and T. Condon. 1994. Ultrasound diagnosis of pregnancy in cattle. Vet. Rec. 134:532.

Moreira, F., R. L. de la Sota, T. Diaz, and W. W. Thatcher. 2000a. Effect of day of the estrous cycle at the initiation of a timed 
artificial insemination protocol on reproductive responses in dairy heifers. J. Anim. Sci. 78:1568-1576.

Moreira, F., C. A. Risco, M. F. A. Pires, J. D. Ambrose, M. Drost, and W. W. Thatcher. 2000b. Use of bovine somatotropin in lactating dairy cows receiving timed artificial insemination. J. Dairy Sci. 83:1237-1247.

Moreira, F., C. Orlandi, C. A. Risco, R. Mattos, F. Lopes, and W. W. Thatcher. 2001. Effects of presynchronization and bovine somatotropin on pregnancy rates to a timed artificial insemination protocol in lactating dairy cows. J. Dairy Sci. 84:1646-1659.

Navanukraw, C., L. P. Reynolds, A. T. Grazul-Bilska, D. A. Redmer, and P. M. Fricke. 2002. Effect of presynchronization on pregnancy rate to a timed artificial insemination protocol in lactating dairy cows. J. Dairy Sci. 85(Suppl. 1):263. (Abstr.)

Pieterse, M. C., O. Szenci, A. H. Willemse, C. S. A. Bajcsy, S. J. Dieleman, and M. A. M. Taverne. 1990a. Early pregnancy diagnosis in cattle by means of linear-array real-time ultrasound scanning of the uterus and a qualitative and quantitative milk progesterone test. Theriogenology 33:697-707.

Pieterse, M. C., M. A. Taverne, T. A. Kruip, and A. H. Willemse. 1990b. Detection of corpora lutea and follicles in cows: a comparison of transvaginal ultrasonography and rectal palpation. Vet. Rec. 156:552-554.

Pursley, J. R., J. S. Stevenson, and J. E. Minton. 1993. Ovarian follicular waves in dairy cows after administration of gonadotropin-releasing hormone at estrus. J. Dairy Sci. 76:2548-2560.

Pursley, J. R., M. O. Mee, and M. C. Wiltbank. 1995. Synchronization of ovulation in dairy cows using $\mathrm{PGF}_{2 \alpha}$ and $\mathrm{GnRH}$. Theriogenology 44:915-923.

Pursley, J. R., M. R. Kosorok, and M. C. Wiltbank. 1997a. Reproductive management of lactating dairy cows using synchronization of ovulation. J. Dairy Sci. 80:301-306.
Pursley, J. R., M. C. Wiltbank, J. S. Stevenson, J. S. Ottobre, H. A. Garverick, and L. L. Anderson. 1997b. Pregnancy rates per artificial insemination for cows and heifers inseminated at a synchronized ovulation or synchronized estrus. J. Dairy Sci. 80:295-300.

Pursley, J. R., R. W. Silcox, and M. C. Wiltbank. 1998. Effect of time of artificial insemination on pregnancy rates, calving rates, pregnancy loss, and gender ratio after synchronization of ovulation in lactating diary cows. J. Dairy Sci. 81:2139-2144.

Sartori, R. 2002. Ovarian function, circulating steroids, and early embryonic development in dairy cattle. Ph.D. Thesis, Univ. of Wisconsin, Madison.

Sartori, R., R. Sartor-Bergfelt, S. A. Mertens, J. N. Guenther, J. J. Parrish, and M. C. Wiltbank. 2002. Fertilization and early embryonic development in heifers and lactating cows in summer and lactating and dry cows in winter. J. Dairy Sci. 85:2803-2812.

SAS User's Guide: Statistics. 1989. Version 6 Edition. SAS Institute Inc, Cary NC

Savio, J. D., M. P. Boland, and J. F. Roche. 1990. Development of dominant follicles and length of ovarian cycles in post-partum dairy cows. J. Reprod. Fertil. 88:581-591.

Vasconcelos, J. L. M., R. W. Silcox, J. A. Lacerda, J. R. Pursley, and M. C. Wiltbank. 1997. Pregnancy rate, pregnancy loss, and response to heat stress after $\mathrm{AI}$ at 2 different times from ovulation in dairy cows. Biol. Reprod. 56(Suppl 1):140. (Abstr.)

Vasconcelos, J. L. M., R. W. Silcox, G. J. M. Rosa, J. R. Pursley, and M. C. Wiltbank. 1999. Synchronization rate, size of the ovulatory follicle, and pregnancy rate after synchronization of ovulation beginning on different days of the estrous cycle in lactating dairy cows. Theriogenology 52:1067-1078.

Vukasinovic, N. 1999. Application of Survival analysis in breeding for longevity. Pages 3-10 in Interbull Bulletin No. 21, Uppsala, Sweden. 